\title{
Sustainability and tool wear of titanium alloy thread cutting in dry and cryogenic conditions
}

\author{
Anna Zawada-Tomkiewicz ${ }^{1} \cdot$ Łukasz Żurawski $^{1}$ - Dariusz Tomkiewicz ${ }^{1} \cdot$ Filip Szafraniec $^{1}$
}

Received: 14 October 2020 / Accepted: 31 March 2021 / Published online: 15 April 2021

(C) The Author(s) 2021

\begin{abstract}
The article is devoted to the study of the effect of cryogenic cooling on the tool wear in thread turning tests. The tool wear and its influence on the thread accuracy were investigated. Two different grades of titanium alloys were used for comparative purposes. The excellent performance characteristics of titanium alloys pose machining problems, causing high unit forces at the edge of the tool leading to chipping and premature tool failure. In turn, the low thermal conductivity of pure titanium affects the heat distribution in the cutting zone. The heat is not absorbed by the material being machined but accumulates in the tool, causing an increase in diffusion and chemical wear. The results of cutting tests using liquid nitrogen showed lower values of wear on the major and minor tool flank. The edge reduction of the tool was also significantly less during cryogenic machining. The analysis of the formation of wear marks and the blade wear mechanisms was carried out for the tool rake face. The tests were carried out using the SEM method and confirmed by EDS analyses. In order to compare the course of tool wear over time, a mathematical model was developed, which results from the course of phenomena during cutting. It consists of two complementary equations. The first equation is characteristic for the first cutting phase and results from the loads imposed on the blade and aims at thermodynamic equilibrium. It is a period of stable tool operation and constant wear intensity. The second equation concerns crossing the equilibrium point followed by the process of accumulation of elementary wear phenomena. These phenomena accumulate until the blade is completely worn-out. The use of blade wear development models to determine the expected blade life allowed to confirm the beneficial effect of cryogenic cooling on the course of the blade wear process when cutting threads for two different titanium alloys.
\end{abstract}

Keywords Thread turning $\cdot$ Titanium alloys $\cdot$ Liquid nitrogen $\cdot$ Tool wear model

\section{Introduction}

Materials for medical uses, including titanium alloys, require a manufacturing process with controlled properties and precision for both internal and external threads. What is advantageous in the long and safe exploitation of a titanium thread translates into difficulties in its machining. The high corrosion resistance and high temperatures of titanium alloys during operation result in accelerated tool wear, vibration, and low material removal rate (MMR) during their processing. As was investigated by Akyildiz in [1], under intensive thermal effects

Anna Zawada-Tomkiewicz

anna.zawada-tomkiewicz@tu.koszalin.pl

1 Faculty of Mechanical Engineering, Koszalin University of Technology, Koszalin, Poland during the cutting process, the stresses at the thread root become tensile. Such stresses weaken the thread especially in terms of fatigue resistance. In order to reduce this effect in the case of a mechanically reliable thread, several defend steps have been taken, including the selection of cutting parameters, selection of the tool and machining method, and lowering the temperature in the cutting zone.

The machinability of titanium alloys is strongly dependent on the cutting parameters, which in turn determine the amount of heat released and the temperature in the cutting zone. As stated in [2], the heat generated during the machining of Ti$6 \mathrm{Al}-4 \mathrm{~V}$ alloy has been identified as the cause of increased tool wear and surface finish degradation, which is characterized by burr formation. Yumak et al. in [3] explained the deflection and springback of the material under the action of cutting force. The machined surface during cutting is thermally softened and, consequently, an unfavorable, brittle alpha phase is formed. Even under conditions where phase change was not observed, the 
high temperature in the cutting zone created a softened zone below the surface, which transformed into burrs. These phenomena begin to occur with greater intensity, where the cross sections of the cut layers are larger and where the cutting edge is subjected to high loads. This was also confirmed in [4], where the consequence of the high load was not only rapid cratering and plastic deformation of the cutting edge but also structural changes in the surface layer. As this tendency increases with cutting time and tool wear, titanium alloys are typically machined at a low cutting speed to prevent the temperature from rising excessively in the cutting zone. As a consequence, in thread cutting, the entire machining allowance is divided into parts. Depending on the size of the thread, it is from a few to a dozen or so infeeds of the tool.

The different grades of titanium alloys differ significantly in their machinability, i.e., their ability to deform, fracture, and withstand stress, strain, and temperature during machining. Due to the fact that titanium, during machining, tends to reach extreme temperatures at the tool/workpiece interface (even above $1000^{\circ} \mathrm{C}$ ), various additives can be used to stabilize the allotropic transformation, as shown in [5]. As reported in [6] for the commercially available pure titanium at cutting speeds above $0.03 \mathrm{~m} / \mathrm{s}$, thermal softening may cause local shear changes and instabilities. Aramcharoen in [7] also confirms the shear instability of chips. Chip analysis carried out in [8] showed their sawtooth nature with a tendency to greater continuity with increasing cutting speed. Along with the decrease in the cutting speed, a weaker thermal softening effect was obtained and a deformation deviating from adiabatic conditions. Also, the adhesion and diffusion phenomena were less intense under such conditions.

It follows from the above considerations that the biggest problem when machining titanium is the high temperature in the cutting zone, the consequences of which go beyond the direct impact on the workpiece. High temperature affects the entire cutting process and causes excessive and accelerated tool wear. High wear intensity also reduces the ability to control the process and achieve the assumed accuracy of the thread. As stated in [9], the tool wear mechanism was a consequence of the high temperature at the interface between the blade and the workpiece and was identified as a combination of dissolution/diffusion and abrasion processes. Cutting titanium alloys results also in a build-up layer and build-up edge on the cutting edge for a wide range of cutting parameters. Cutting with a tool with significant wear causes deterioration of surface finish.

From the above considerations in the field of machining threads made of titanium alloys, it follows that in order to improve the machinability and quality of the thread produced, the cutting tool that receives most of the cutting heat should be cooled. In the case of the machining of titanium alloys for medical applications, it is inappropriate to use conventional cooling in the form of an emulsion or oil, as this causes the build-up of the coolant in irregularities on the surface and the possibility of accelerated development of the microenvironment in which microorganisms thrive. In contrast, the use of cryogenic fluids to cool the cutting zone is bioactive and ecological. The liquid nitrogen used for cooling evaporates and leaves the workpiece, chips, and machine tool clean [2].

Conclusions from numerous studies on temperature reduction in the cutting zone indicate a beneficial effect of cryogenic cooling in comparison with conventional flooding, MQL and dry machining processes [10]. It has been shown in [11] that cryogenic machining can lead to a reduction of cutting forces by at least $15 \%$ for lower cutting conditions compared to flood coolant. It was shown in [12] that the feed force decreased because the material became less sticky and less ductile. Although no change in the feed force was confirmed in [13], it was indicated that the main cutting force decreased, which was also confirmed in [14]. At the same time, as presented in [15], the use of liquid nitrogen can effectively reduce the wear of cutting tools while stabilizing the cutting conditions and improving surface integrity. In cryogenic cooling, the machinability of titanium alloys is significantly improved $[16,17]$. The lowered temperature in the cutting zone resulted not only in a quantitative reduction in the tool wear (lower tool nose wear and reduction of tool cratering) but also changed the wear mechanisms: the dominant adhesive wear was changed to abrasive [18-20]. Similar conclusions were drawn from the work [21], which showed that the cooling technique strongly depends on a pair of materials: workpiece, blade. However, both reviews emphasized that the transfer of heat generated during cutting by the cryogenic fluid lowers the cutting temperature, which in turn can be used to increase cutting parameters and MRR.

As stated in [22], when using cryogenic thermal annealing, the hardness of the titanium alloy increased with increasing dislocation and twin density. Hong et al. in the work [23] showed an increase in strength compared to room temperature due to the improvement and stabilization of the structure of the crystal lattice. It was also explained that low temperatures block displacements in the material, causing the domination of elastic strains throughout the fatigue life. The cryogenic treatment itself and the cryogenic treatment before aging described in [24] confirm the improvement of the plasticity of the Ti-6Al-4V alloy. In the analysis of surface integrity in the cryogenic treatment of Ti-6Al-4V alloy discussed in [25], an increase in surface hardness and a reduction in grain size have been reported. It was also found that the cryogenic treatment gave the lowest values of surface roughness in all the cutting conditions tested $[26,27]$.

The research described in this article focuses on the development of tool wear during thread cutting tests of grade 2 and grade 5 titanium alloys under dry and cryogenic conditions. When cutting at ambient temperature, the coated sintered carbides were applied and parameters were selected to maintain 
the longest tool life. For cryogenic cutting, uncoated sintered carbides were used to prevent the coating delamination for extreme temperature conditions. The tool wear was evaluated experimentally by means of SEM and EDS analysis coupled with optical microscopy.

Contribution of this work focuses on describing the wear mechanism of tungsten carbide tool under dry and cryogenic conditions. The wear patterns on the rake face were analyzed at different magnifications using SEM. Additional EDS analyses confirmed the complex wear mechanisms of the carbide blade and the anti-wear coating. Quantitative research in the field of tool edge reduction and tool blunting on the main and minor cutting edges (major flank and minor flank), which directly affects the quality of the thread, was carried out using an optical microscope. The tests were carried out for the successive infeeds of the tool. For the purpose of comparing the tool wear intensity with regard to the thread quality, a model of wear development over time was elaborated. The model consists of two complementary equations relating to the development of the wear process over time. The equation of the first model represents the initial cutting stage, in which the unit forces are saturated and the thermodynamic equilibrium is sought. The equation of the equilibrium exit model means the accumulation of wear phenomena depending on the heat absorbed by the tool and other wear phenomena. The model developed in this way enables a comparative analysis of the development of tool wear over time, forecasting changes on the cutting edge and compensation of the tool position as a result of tool edge reduction.

\section{Materials and methods}

External thread M-ISO M7×1 (ISO 68-1: 1998 [28]) cutting tests were performed for two different titanium alloys:

- Annealed commercially pure titanium grade 2 consisted of $100 \%$ alpha phase, hardness of $80 \mathrm{HRB}$, modulus of elasticity of $105 \mathrm{GPa}$, and thermal conductivity of $16.4 \mathrm{~W} / \mathrm{m}$ $\mathrm{K}$ (annealed) (Table 1).

- $\alpha \beta$ Titanium alloy grade 5, a Ti-6Al-4V composite, consisted of $6 \mathrm{wt} \% \mathrm{Al}$ and $4 \mathrm{wt} \% \mathrm{~V}$, hardness of 36 HRC, modulus of elasticity $113.8 \mathrm{GPa}$, and thermal conductivity $6.7 \mathrm{~W} / \mathrm{m}-\mathrm{K}$ (Table 1)..

The cutting tests were performed in ambient and cryogenic conditions: for cutting in ambient conditions, 'Ti grade 2, dry' and 'Ti grade 5, dry'; for cryogenic machining (5 minutes of workpiece cooling before machining), 'Ti grade 2, LN2' and 'Ti grade 5, LN2'. There were prepared 32 samples of $40 \mathrm{~mm}$ length with a diameter of $7 \mathrm{~mm}$, an example of which, after machining, is shown in Fig. 1.
Attempts to select and optimize cutting parameters for machining titanium alloys have been undertaken by many research centers and tool manufacturers. Pramanik and Littlefair in [29] have indicated the titanium alloy as a material of difficult machinability, due to properties such as sawtooth chip formation and the low thermal conductivity of the alloy. Low thermal conductivity causes local high temperatures, which cause shear instability during chip formation, while sawtooth changes the chip thickness leading to local temperature variations. Despite these difficulties, as has been demonstrated in [8], the optimization procedures usually used for other alloys can also be applied successfully to titanium alloys (by adjusting the cutting conditions). These studies are supported by cutting process modeling presented in [30], which shows that in Ti-6Al-4V cutting in the chip forming process, thermal softening as a result of strong local heating is dominant.

Two different tool materials were used in the ambient temperature cutting and cryogenic cutting tests: for thread turning at ambient temperature, PVD TiAlN-coated thread inserts (3ER 1.0 ISO VTX Vardex carbide threading inserts [31]) were used. In the cryogenic threading tests, uncoated P30 carbide inserts (Carmex 16 ER 1.0 ISO P30 [32]) were used because, as shown in [33], the cryogenic treatment weakens the interfacial bonding of the coating to the substrate, leading to coating delamination.

Cutting parameters have been pre-optimized for tool life. Finally, cutting tests were performed for the following parameters: feed rate $1 \mathrm{~mm} / \mathrm{rev}$, cutting speed $22 \mathrm{~m} / \mathrm{min}$ (rotational speed $1000 \mathrm{rev} / \mathrm{min}$ ), and infeeds $1-0.1 \mathrm{~mm}, 2-0.1 \mathrm{~mm}, 3-0.1$ $\mathrm{mm}, 4-0.1 \mathrm{~mm}, 5-0.1 \mathrm{~mm}, 6-0.06 \mathrm{~mm}, 7-0.05 \mathrm{~mm}$, and 8$0.05 \mathrm{~mm}$. According to the results presented in [30], the selected cutting speed and non-deformed chip thickness may result in the formation of non-periodic sawtooth chips and the possibility of faster tool wear.

\section{Results and discussion}

When examining titanium alloys in thread turning tests at room temperature and cryogenic conditions, the tool failure mechanism was recognized as adhesion-diffusion and all tools were subjected to this failure mode. Apparently, under room temperature conditions, the process becomes adiabatic with limited possibilities for heat dissipation. As a consequence, the condition of the tool deteriorates rapidly. To prevent this or to reduce tool wear, one solution is to use coated tools; another is the removal of heat from the cutting zone-in extreme cases by cryogenic cooling. Bermingham et al. in [34] compared the technologies of cryogenic and high-pressure cooling. Their results showed that the friction coefficient on the 
Table 1 Specification of the titanium alloys

\begin{tabular}{|c|c|c|c|c|c|c|c|c|c|}
\hline \multicolumn{10}{|c|}{ Chemical analysis $\%$} \\
\hline & $\mathrm{N}$ & $\mathrm{C}$ & $\mathrm{H}$ & $\mathrm{Fe}$ & $\mathrm{V}$ & Al. & $\mathrm{O}$ & $\mathrm{Ti}$ & Other \\
\hline Ti grade 2 & 0.01 & 0.02 & 0.001 & 0.06 & 0 & 0 & 0.12 & 99.689 & 0.1 \\
\hline Ti grade 5 & 0.001 & 0.03 & 0.001 & 0.14 & 4.14 & 5.85 & 0.14 & 89.598 & 0.1 \\
\hline \multicolumn{10}{|c|}{ Mechanical properties } \\
\hline & \multicolumn{3}{|c|}{ Yield strength $0.2 \%$} & \multicolumn{2}{|c|}{ Tensile strength } & \multicolumn{2}{|c|}{ Elongation } & \multicolumn{2}{|c|}{ Reduction of area } \\
\hline Ti grade 2 & \multicolumn{3}{|c|}{$350 \mathrm{MPa}$} & \multicolumn{2}{|c|}{$467 \mathrm{MPa}$} & \multicolumn{2}{|l|}{$33 \%$} & \multicolumn{2}{|l|}{$57 \%$} \\
\hline Ti grade 5 & \multicolumn{3}{|c|}{$905 \mathrm{MPa}$} & \multicolumn{2}{|c|}{$980 \mathrm{MPa}$} & \multicolumn{2}{|l|}{$18 \%$} & \multicolumn{2}{|l|}{$51 \%$} \\
\hline
\end{tabular}

surfaces of the tool-chip joints in some cases increased compared to dry machining, and the wear mechanism still indicated adhesive-diffusion wear of the material. Similar conclusions have been confirmed by Rotella et al. [25], where it was clearly stated that there is no impact on the friction coefficient under cryogenic cooling. Cryogenic coolants have little effect on the lubrication of the cutting process. Nevertheless, in studies presented in [35], many different cryogenic cooling technologies have been studied, indicating their effectiveness in the context of tool wear, i.e., average flank wear, maximum flank wear, notch wear, and nose wear. Generally, several tool wear mechanisms take place simultaneously and affect one another, which deteriorate and weaken the cutting tool and promote the propagation of existing cracks. The exemplary methodology of tool wear measurements has been presented in [36], where SEM and EDS have been used to confirm the influence of microhardness and microstructure of titanium alloys on tool wear in dry machining.

In the work, SEM images and EDS analyses were obtained using the Phenom G2 pro scanning microscope. Images were taken at a magnification of $\times 265, \times 600$, and $\times 1300$. Lower magnifications were used to view the entire rake face of the cutting tool. In the case of a magnification of $\times 600$, it was used for the analysis of abrasive and adhesive wear mechanisms and EDS analysis. When it was necessary to confirm the wear mechanisms, even greater $\times 1300$ magnification was used. Such a large magnification made it possible to view the details of the tool damage mechanisms.

Measurements of wear on the tool's flank and rake faces were made with the use of an optical microscope, which made it possible to obtain images with a size of $1.47 \times 1.13 \mathrm{~mm}$ for the rake face and $0.84 \times 0.65 \mathrm{~mm}$ for the flank face. The data from the optical microscope were used for quantitative

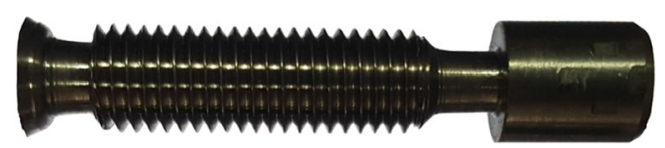

Fig. 1 Thread produced from Ti grade 2, LN2 analysis of the wear of the cutting tool and for the elaboration of a model of the development of the tool wear over time.

\subsection{Wear of coated tungsten carbide tool}

When cutting an external thread for eight consecutive passes, the cutting speed has been optimized to obtain the longest possible life for coated tungsten carbide (WC-Co) when dry cutting. Given the high cutting zone temperature when machining a titanium alloy, diffusion and adhesion were expected to be the dominant wear mechanisms. Initial studies of the machining of titanium alloys confirmed the adhesion of the workpiece material to the cutting tool. The properties of the tool coating have been selected in such a way as to counteract adhesion and thus reduce adhesive wear. The TiAIN coating was also chosen for its low thermal conductivity and antioxidant wear even at $900^{\circ} \mathrm{C}$.

Despite the low cutting speed, machining titanium alloys was still a challenge. Images of the tools after the end of the experiment are shown in Figs. 2, 3, and 4. It turned out that both grades of titanium alloys are difficult to cut. They caused weakening of the TiAlN layer of the tool and softening of the substrate material of the tool. Eventually, some of the coating was delaminated and removed, which in turn exposed brittle tungsten carbide particles. The TiAlN coating has been removed by abrasion, leaving the uncoated substrate exposed to direct contact with the workpiece and the flowing chips. The map of tungsten for both grades of titanium alloy confirms the exposure of tungsten carbide (Fig. 2). The SEM image (Fig. 3) shows a fragment of a fine tungsten carbide structure with a grain size below $1 \mu \mathrm{m}$ (Fig. 3c).

Similarly, the adhesion of the workpiece material to the tool (built-up edge) allowed the tool material to be torn off by passing chips. This is clearly seen in the SEM image and EDS analysis as the adhesive material with uneven distribution moves along the tool during subsequent infeeds (Fig. 3d). This image shows the exposed part of the tool with visible TiAlN coating. Chips adhered to the edge of the tool are in the segmented (serrated) form (Fig. 3b). These chips are visible on the side of the main tool flank face and the tool cutting nose 

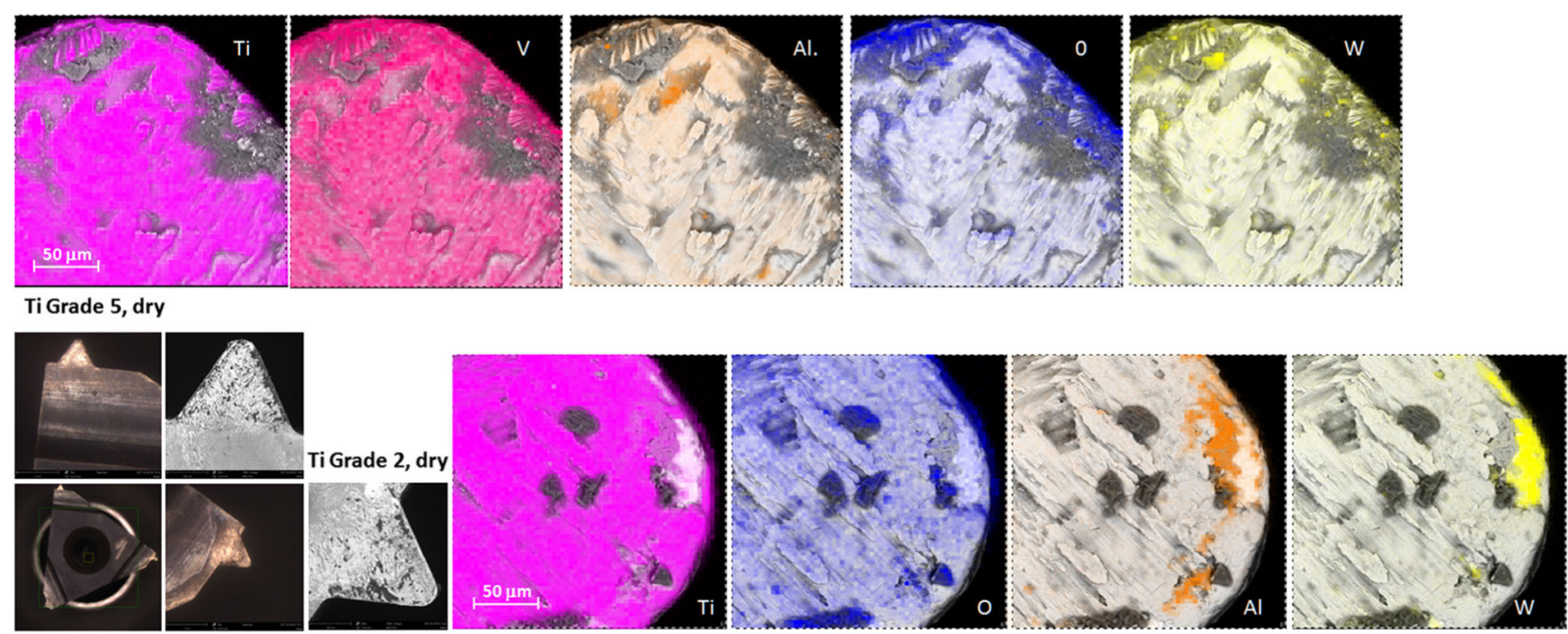

Fig. 2 EDS of rake face of TiAlN-coated tool after cutting of Ti grade 2 dry and Ti grade 5 dry

(Fig. 3a). On the side of the minor tool flank face, glued layers of material that do not have such a segmented form are visible.

No segmented chips can be observed on the tool rake surface when cutting $\mathrm{CP}$ Ti grade 2. The numerous built-up layers and built-up edges adhered to the tool cover a large part of tool rake face (Fig. 4). This conclusion was drawn from the EDS analysis, where oxygen can be found in the composition (point 2), and the system identifies the material as $\mathrm{TiO}_{2}$. A fragment of the exposed and damaged coating is also visible on the rake face of the tool, in the chip flow area where the temperature and load are highest. This is evidenced by the EDS analysis performed in the area of the damaged coating (point 1). In this area, fragments of the TiAlN coating and WC-Co tungsten carbide substrates can be distinguished.
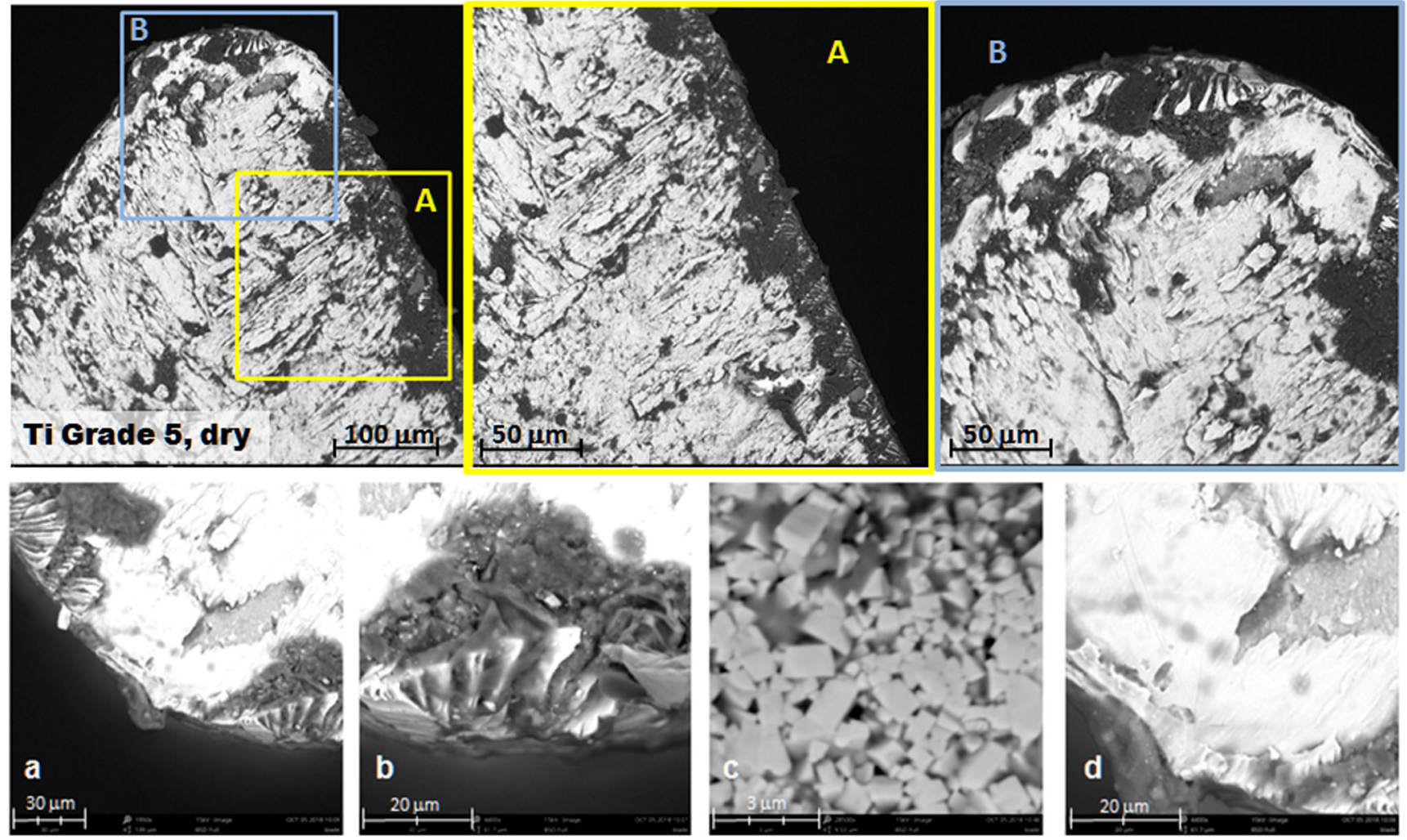

Fig. 3 SEM images of rake face of TiAlN-coated tool after cutting of Ti grade 5 dry 

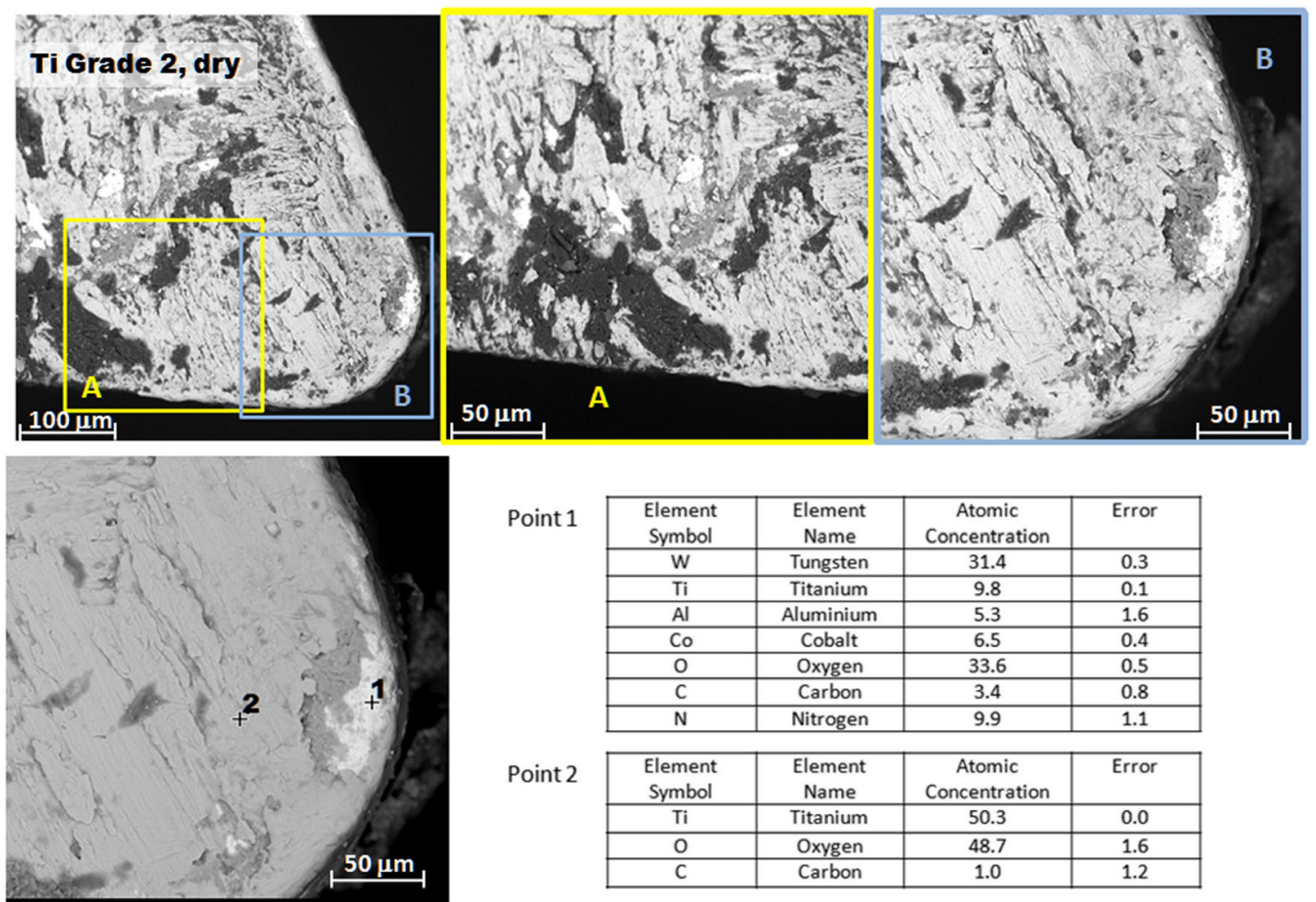

Point 1

\begin{tabular}{|c|c|c|c|}
\hline $\begin{array}{c}\text { Element } \\
\text { Symbol }\end{array}$ & $\begin{array}{c}\text { Element } \\
\text { Name }\end{array}$ & $\begin{array}{c}\text { Atomic } \\
\text { Concentration }\end{array}$ & Error \\
\hline $\mathrm{W}$ & Tungsten & 31.4 & 0.3 \\
\hline $\mathrm{Ti}$ & Titanium & 9.8 & 0.1 \\
\hline $\mathrm{Al}$ & Aluminium & 5.3 & 1.6 \\
\hline $\mathrm{Co}$ & Cobalt & 6.5 & 0.4 \\
\hline $\mathrm{O}$ & Oxygen & 33.6 & 0.5 \\
\hline $\mathrm{C}$ & Carbon & 3.4 & 0.8 \\
\hline $\mathrm{N}$ & Nitrogen & 9.9 & 1.1 \\
\hline
\end{tabular}

Point 2

\begin{tabular}{|c|c|c|c|}
\hline $\begin{array}{c}\text { Element } \\
\text { Symbol }\end{array}$ & $\begin{array}{c}\text { Element } \\
\text { Name }\end{array}$ & $\begin{array}{c}\text { Atomic } \\
\text { Concentration }\end{array}$ & Error \\
\hline $\mathrm{Ti}$ & Titanium & 50.3 & 0.0 \\
\hline $\mathrm{O}$ & Oxygen & 48.7 & 1.6 \\
\hline $\mathrm{C}$ & Carbon & 1.0 & 1.2 \\
\hline
\end{tabular}

Fig. 4 SEM images and EDS analysis of rake face of TiAlN-coated tool after cutting of Ti grade 2 dry

\subsection{Wear of uncoated tungsten carbide tool}

The cooling capabilities of LN2 have been confirmed for both titanium alloys. Despite the cryogenic cutting conditions for both titanium alloys, layers of material were found on the face of the tool as well as on the major and minor flanks. Clear evidence that the adhesion mechanisms worked during the tests was identified by SEM and EDS analysis (Figs. 5 and 6). The reasons for such high adhesion are high forces and still high cutting temperature, together with the high chemical reactivity of titanium. Dhananchezian and Kumar in [10] report both a slight reduction in the cutting temperature as a result of cryogenic cooling and the formation of crater wear on the tool rake face caused by adhesion and diffusion. The extreme reactivity of titanium at high temperature can result in high solubility of most elements, including cobalt, carbon, and tungsten tool materials.

However, the cooling effect of LN2 appears to have little effect on the coefficient of friction. Courbon et al. in [37] discuss the tribological behavior of Ti6Al4V in machining with carbide tools. Among other things, they state that the friction coefficient remains almost the same for all cutting tests. Kaixuan et al. in [22] report a low lubrication effect with even intensive cryogenic cooling. These tribological tests show that LN2 cooling has little effect on the friction coefficient. Nevertheless, it was found that the cryogenic treatment has a significant positive effect on cemented carbides, causing the martensitic transformation of cobalt and stable tungsten

a)
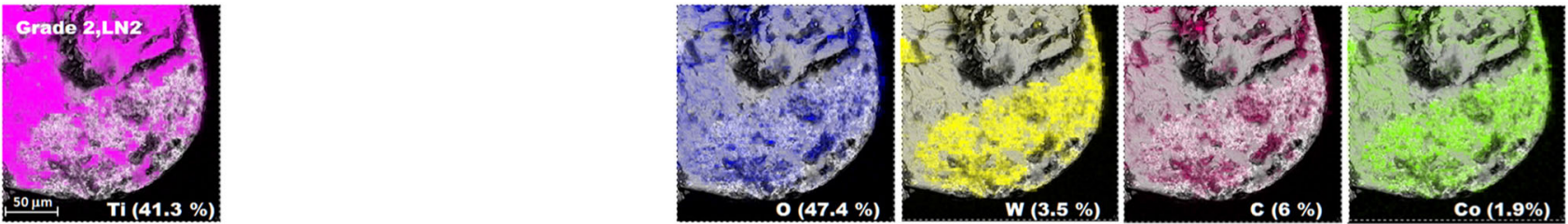

b)
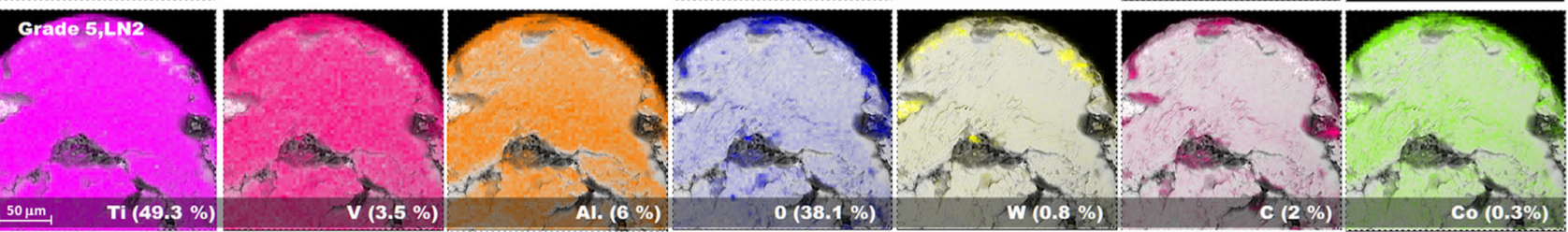

Fig. 5 EDS maps of rake face of tungsten carbide tool after cutting of Ti grade 2 LN2 (a) and Ti grade 5 LN2 (b) 
a)
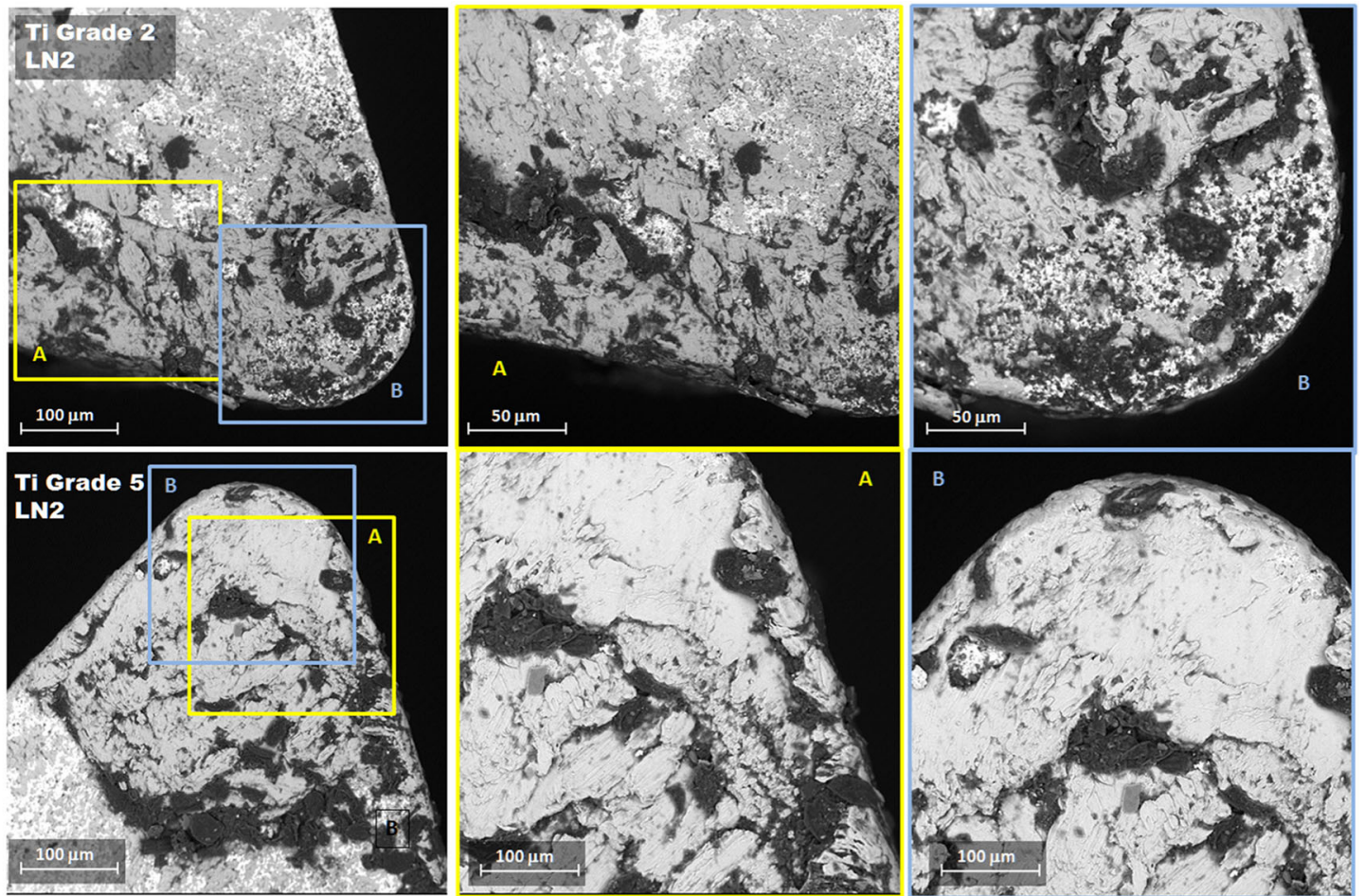

b)
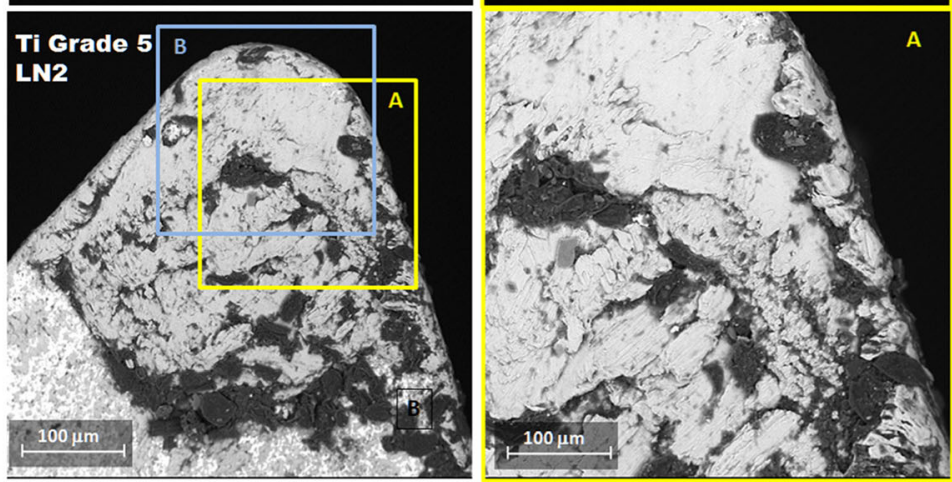

Fig. 6 SEM images of rake face of tungsten carbide tool after cutting of Ti grade 2 LN2 (a) and Ti grade 5 LN2 (b)

carbide. The use of cryogenic cutting may affect the tool, resulting in an increase in thermal conductivity [38] and an increase in the hardness [39] and bending strength [40] of the cemented carbides, resulting in greater wear resistance.

The extreme cooling conditions by cryogenic freezing of the workpiece lowered the temperature in the cutting zone. However, the temperature remained so high that conditions were still in place to allow the tool components to diffuse and adhere to the chips and to bond the workpiece material to the tool surfaces. When thread cutting under liquid nitrogen conditions for Ti grade 2 (Fig. 5a), a large part of rake face was covered with oxidized material, with only the cutting edges exposed. Atomic concentration analysis shows $\mathrm{Ti} / \mathrm{O}$ as the dominant component $(88.7 \%)$, the remainder being exposed tool material (WC-Co).

When machining a grade 5 titanium alloy (Fig. 5b), the material sticks to the tool. The tungsten distribution map shows that there is no work material stuck on the cutting edge of the tool and the tool material (WC-Co) is visible. The transition temperature between brittleness and ductility may explain the delamination of the workpiece material on the rake face of the tool. Due to the heavy load on the exposed cutting edge, chipping occurred during thread cutting. This is visible in the gray inhomogeneities in the SEM image of the cutting edge (Fig. 6a and b). These are the traces of successive infeeds. The interpretation of the formation of grooves relates to the plastic deformation of the material. A similar interpretation can be found in Sartori et al. [27] discussing grooving with the explanation that it was most likely caused by plastic deformation when the carbide particles are detached and removed from the chip/tool interface.

\subsection{Measurement of wear on the tool's flank face}

Observation of tool wear by means of optical microscopy confirms a similar pattern of tool wear in both dry and cryogenic machining. However, different wear mechanisms were identified and different wear rates were calculated depending on the cooling of the cutting zone.

In both dry and cryogenic turning, workpiece adhesion was the most noticeable wear mechanism. Other wear mechanisms for the tool flank face include abrasion and chipping. The application of cutting conditions with LN2 clearly influenced the tool wear modes, as shown by optical images compared to dry-turned threads (Fig. 7).

Chipping was observed at the cutting edge during cryogenic cutting using uncoated cemented carbides. Chipping was caused by the detachment of less adhesive parts of the blade under the layers of bonded material that has been welded to the surface of the tool from the very beginning of the cutting process. This may indicate that even the chipping process is initially activated by the adhesive wear mechanism. The toolchip contact length represents the length of seizure and the frictional interface that generates heat along the deformation zone of the material being cut. The attempts to cut the thread took place in stages, in which the tool cuts the previously strengthened material in the next infeed. 


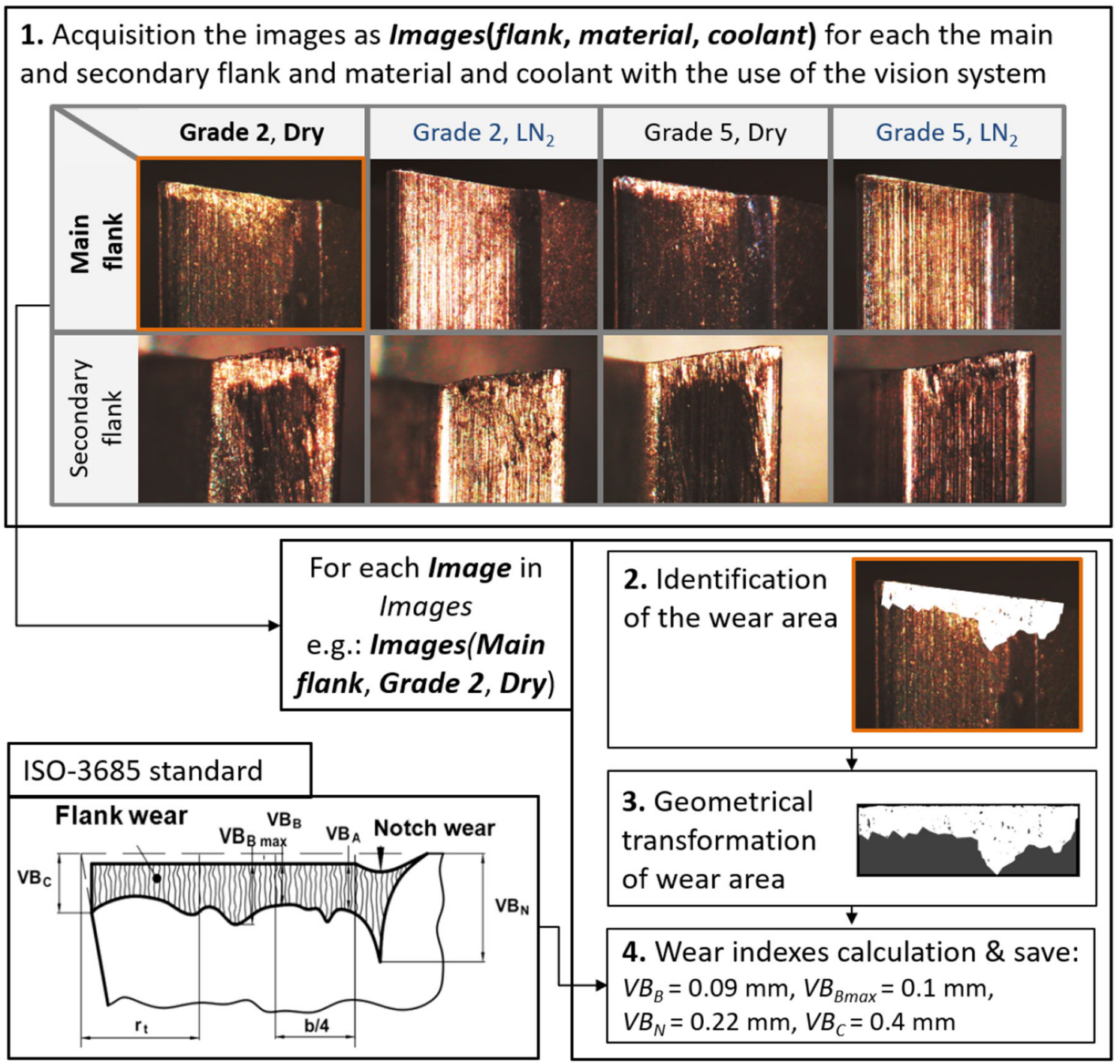

Fig. 7 Specification of measurements of the major and minor flank of the tool

The measurements in these tests related to the registration of the tool images and the thread profile after each infeed. There were 32 measuring points in total; the measurements were repeated three times. Measurements of the tool flank wear were analyzed:

1. Cutting wedge-major flank $A \alpha$-indexes of tool flank wear: $V B_{B}, V B_{B \max }, V B_{N}, V B_{C}$ (on the nose rounding)

2. Cutting wedge-minor flank $A \alpha^{\prime}$-indexes of tool flank wear: $V B_{B}^{\prime}, V B^{\prime}{ }_{B \max }, V B_{N}^{\prime}$

To help illustrate the failure modes of the tools under different cutting conditions, the flank face was divided into two parts, a flat flank face and a curved face at the tip of the tool (i.e., tool nose). This was done for both the main and the minor flank of the tool. The tool wear indexes of the main and minor flank were determined using the vision system presented in [41], in which the accuracy of index determination was analyzed. In the optical method, the wear area is automatically identified in the tool flank image and the tool wear indexes are calculated with a measurement accuracy of $4 \mu \mathrm{m}$. First, images of the flank surface are captured, then image processing methods are used to identify the tool wear area (local thresholding with Otsu method), and finally the wear area is geometrically transformed (rotated according to the lines defined by the Hough transform) and tool wear values are determined (the difference between the bottom and top edges of tool wear area scaled with the calibrated physical pixel length).

According to ISO-3685 (1993) [42], the end of tool life occurs when the average flank wear exceeds $0.3 \mathrm{~mm}$ or the maximum flank wear exceeds $0.6 \mathrm{~mm}$, whichever comes first. Since in this case, the main and the minor flank are separated into two parts, and the shortest time is used to reach this criterion either for tool nose wear or tool flank wear. In all cutting tests, the maximum wear rate refers to the nose wear, 
which reached almost $0.6 \mathrm{~mm}$ in dry cutting tests and was significantly greater than in the cryogenic cutting tests. An example of the determination of wear indicators is shown in Fig. 7, and the summary of the test results (indexes according to ISO-3685) in Table 2. It is clear that the use of cryogenic coolant improved the tool life in all tests. In the case of liquid nitrogen cooling, the tool wear was lower: on average by $64 \%$ for Ti grade 2 and by $52 \%$ for Ti-6Al-4V. Due to the temperature generated during cutting, which tends to be concentrated at the cutting edge closest to the nose of the tool, the wear in the curvilinear part $\mathrm{C}$ is the highest, under all cutting conditions for the tested turning time. The values of $V B_{c}$ after $43 \mathrm{~s}$ of turning of Ti grade 2 do not exceed $0.4 \mathrm{~mm}$ for dry cutting and $0.1 \mathrm{~mm}$ for cryogenic cutting. The use of cryogenic cooling reduces the tool nose wear for both titanium alloy grades.

\subsection{Measurement of tool rake face wear}

In order to analyze the machinability of the titanium alloy in thread turning, the change of the tool cutting wedge contour from the side of the rake face for subsequent infeeds was tested. The measurement data processing algorithm is shown in Fig. 8. The stages of data processing include the acquisition of digital images of the rake surface of the tool and their digital processing for the purpose of obtaining the outline of the blade from the side of the tool's rake face. The blade outline is then compared to the metric thread pattern. Based on the comparison, the $K E$ value of the tool edge reduction is determined. The $K E$ value is closely related to both the tool flank wear indexes and the quality of the thread cut (Fig. 9).

The analysis of the rake face contour information allowed assessment of the influence of the cutting time on changes in the geometric shape of the tool, including its edge reduction. Changes in the shape of the tool contour affect the machining accuracy, i.e., the thread geometry. Figure 10 shows the analysis of tool edge reduction in cutting tests of external titanium

Table 2 Tool flank wear indexes: C (curvilinear part), B (straight line between $\mathrm{C}$ and $\mathrm{A}$ ), A ( $1 / 4$ of the length of the active edge, most distant from the corner), $\mathrm{N}$ (notch wear zone)

\begin{tabular}{|c|c|c|c|c|}
\hline & Ti grade 2 & Ti grade $2 \mathrm{LN}_{2}$ & Ti grade 5 & Ti grade $5 \mathrm{LN}_{2}$ \\
\hline \multicolumn{5}{|c|}{ Indexes of major flank wear, mm } \\
\hline$V B_{B}$ & 0.09 & 0.04 & 0.08 & 0.03 \\
\hline$V B_{B \max }$ & 0.10 & 0.05 & 0.10 & 0.05 \\
\hline$V B_{N}$ & 0.22 & 0.05 & 0.32 & 0.04 \\
\hline$V B_{C}$ & 0.40 & 0.1 & 0.56 & 0.15 \\
\hline \multicolumn{5}{|c|}{ Indexes of minor flank wear, $\mathrm{mm}$} \\
\hline$V B_{B}$ & 0.23 & 0.11 & 0.23 & 0.12 \\
\hline$V B_{B \max }$ & 0.20 & 0.07 & 0.17 & 0.1 \\
\hline$V B_{N}$ & 0.37 & 0.10 & 0.25 & 0.25 \\
\hline
\end{tabular}

threads. When cutting the thread, the tool gradually wears out and the outline of the cutting edge changes. This is evident in its shortening and geometry changes. As can be seen, the tool edge reduction is much smaller when liquid nitrogen cooling is used in cutting for both grades of titanium alloys.

As has been shown in many studies, including those reported in [20], the cutting speed, undeformed chip thickness, and the feed rate affect the progress of tool wear. The ANOVA analysis presented in [43] shows that the cutting speed is a more important factor than the feed rate in determining tool life.

In the case of thread turning, the tool life curves have a typical S-shaped profile, with a rapid initial rise, a nearly flat central region, and a final rapid rise. This is especially true with Ti grade 2 dry. The tools used in cryogenic machining have a longer plateau, which provides not only a longer tool life but also a more reproducible and solid cutting performance as the tool geometry has been stable over a longer period of time. Tool wear increased significantly with cutting times of 20 to 30 seconds, which corresponded to a combined time to make two to three threads. The use of liquid nitrogen to cool the cutting zone lowered the tool edge reduction $K E$ but made the blade susceptible to chipping where the material from the previous feed had been strengthened.

Measurement of tool wear both on the rake face and on the main and secondary flanks enabled the construction of wear models describing their relationship with the thread quality.

\subsection{Model of tool wear development}

Tool wear has a direct effect on the quality of the thread. This is all more noticeable when machining threads are made of titanium alloys, where tool wear is accelerated and strongly dependent on the cutting conditions. The problem, then, is how to carry out the cutting process to obtain the desired thread quality under the given cutting conditions. In order to investigate the effect of cutting conditions on the quality of the thread, a model of the wear development over time was developed (Fig. 11), which is a generalized description of the wear process and allows to compare tool wear changes over time depending on the cutting conditions.

The assumptions for the model development are presented below.

1. The model should show the change in tool edge reduction over time. This means that the output of the model should be the value of tool edge reduction $K E$ and the independent variable should be the cutting time.

2. The model should provide tool infeed data taking into account tool edge reduction. This means that the value determined on the basis of the model should enable the prediction of the tool wear during cutting and the 


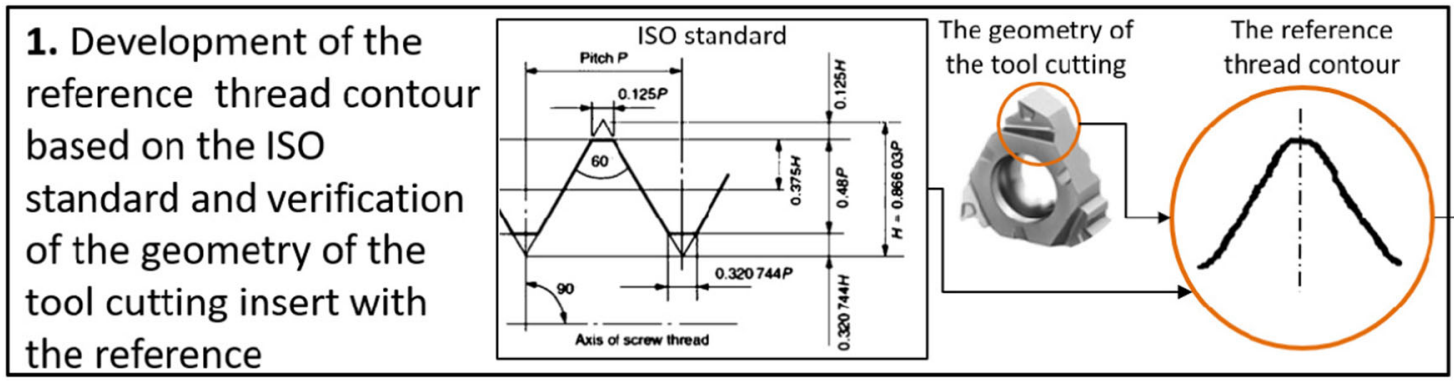

\begin{tabular}{|l|l||}
\hline 2. Acquisition the images of & Images: \\
the blade's rake surface & Materials: \\
using a vision system as & Grade 2, Grade 5 \\
Images(material, coolant, & Coolants: \\
Imag, & Image \\
infeed number) for each the & Infeed numbers: \\
material and coolant and & $\mathbf{1}-\mathbf{0 . 1} \mathbf{m m}, 2-0.1 \mathrm{~mm}$, \\
infeed number & $3-0.1 \mathrm{~mm}, 4-0.1 \mathrm{~mm}, 5-0.1 \mathrm{~mm}$, \\
\hline
\end{tabular}

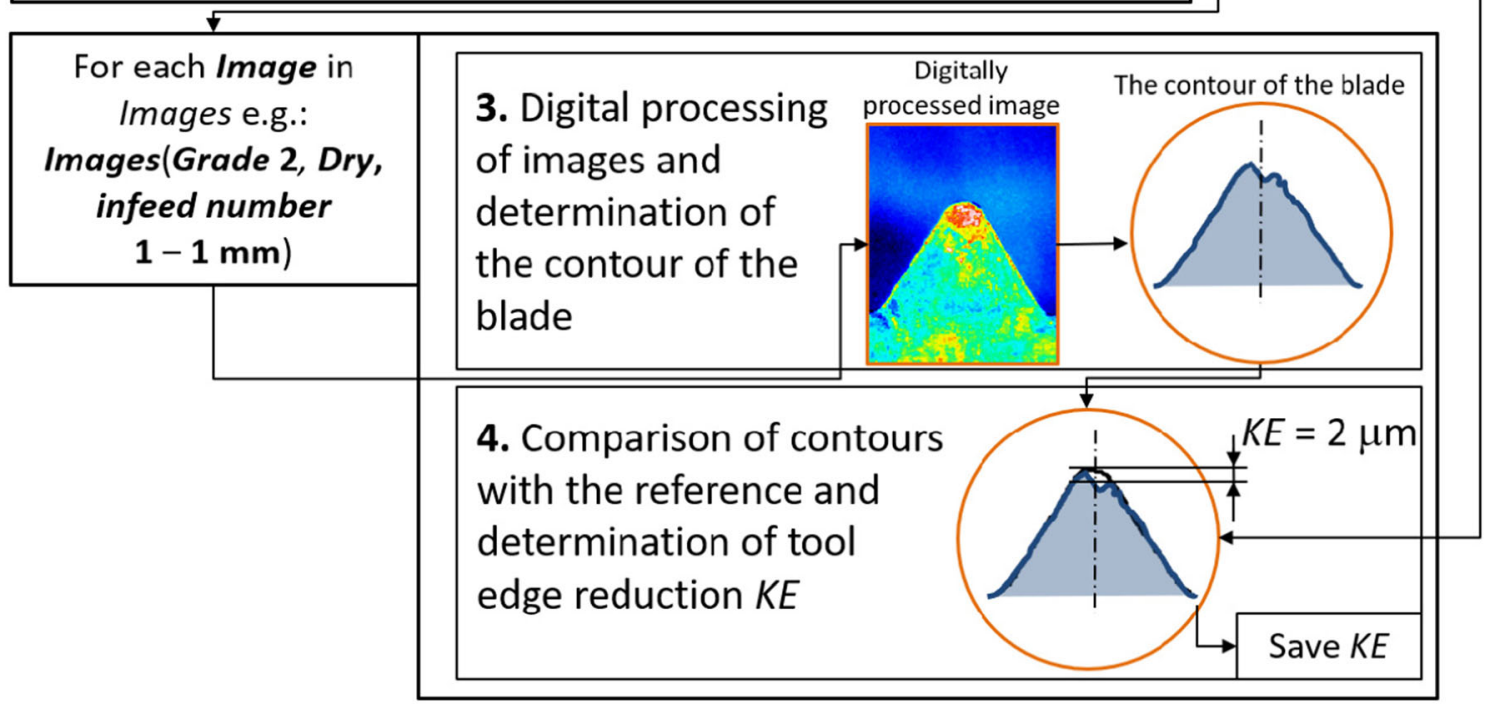

Fig. 8 Analysis of the contour of the wedge from the surface A $\gamma$ in relation to ISO 68-1 (1998) [28]

correction as a position due to the assumed accuracy of the thread.

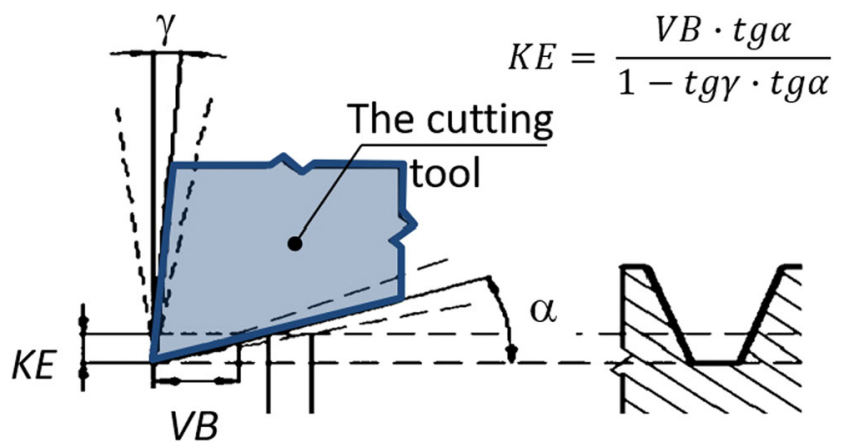

Fig. 9 Relationship between tool edge reduction, VB tool wear index, and thread quality
3. The model should reflect the tool wear progress over time, i.e., typical S-shaped profile, with a rapid initial rise, a nearly flat central region, and a final rapid rise. This means that the model is nonlinear and that it must be taken into account that in $t_{A}$ time the model of wearing process changes.

4. The model should include the tool wear mechanisms. This means that the model parameters must be interpretable in the context of tool edge reduction over time. The parameters must make it possible to assess the intensity of the wear mechanisms over time for various cutting conditions.

5. The model should take into account the constant load during cutting. This means that the model should take into account the load of the cutting process as an input signal. In principle, the undeformed chip thickness for each infeed of the tool had a constant value, which at a constant 

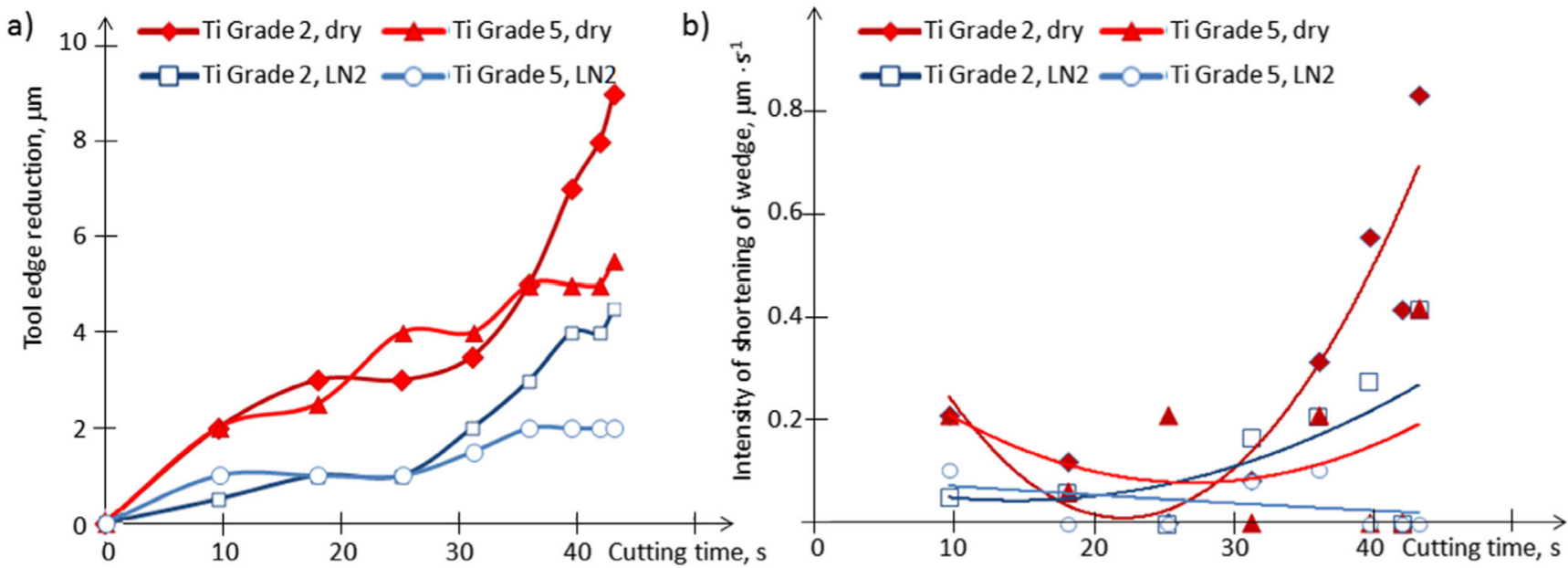

Fig. 10 Tool edge reduction and its intensity vs. cutting time

cutting speed allows for assuming a constant load (material removal rate), described by the unit step function.

The new tool is assumed to be in a steady state. When the thread cutting process is started (input signal), the output signal changes immediately from the current value to a different constant value. Initiating a cutting process causes an energy flow and it is proportional to the potential change of the cutting tool state. The constraint for the system is the material removal rate, which is constant and necessitates the supply of the energy needed to perform the work of plastic deformation and decohesion of the material used for chip formation, frictional forces on the rake and flank surfaces, and plastic deformations preceding the slip and penetrating into the top layer of the cut material. As a result of changes in the cutting edge, the energy required to perform the cutting work changes. In the initial period of cutting, the energy demand increases due to the running-in process of the cutting edge. As time goes on, the increase in energy demand decreases and the process tends to reach a state of equilibrium.
Despite the constant extortion in the form of a constant material removal rate, at some point, the demand for energy begins to increase and the increase is more and more rapid. The demand for energy results from the necessity to perform the cutting work with the unfavorably changing geometry of the tool blade and the intensification of thermal processes.

According to the equations defining the cutting work components, the characteristic methods of removing heat from the chip forming zone include heat carried by the chip, absorbed by the tool tip, conducted to the workpiece, and carried to the atmosphere.

Due to the properties of titanium alloys, the heat is absorbed mainly by the cutting edge of the tool when cutting in an ambient atmosphere. Hence, the transition from the equilibrium state to the process of heat accumulation in the blade and the intensification of the wear phenomena of the blade is very fast. When machining a previously cooled titanium alloy, a much smaller part of the heat is absorbed by the cutting edge of the tool. This is reflected in the model parameters.
Fig. 11 Model of tool wear development over time

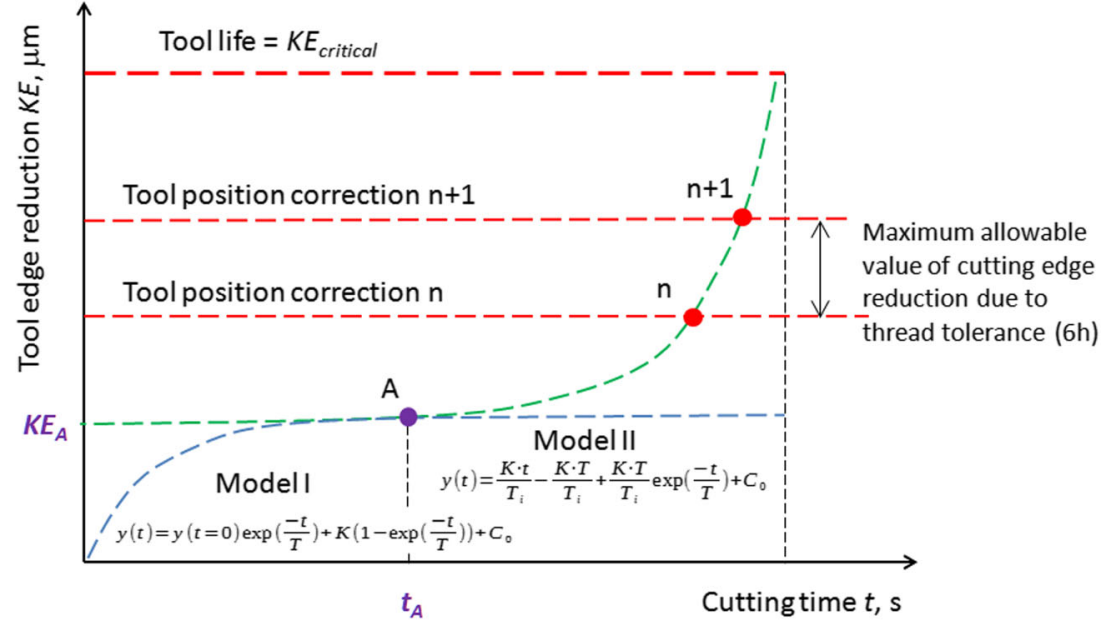


The cutting process gain factor for the first model (Model I) is determined by the relationship of the increase in the output signal to the increase in the input signal from one steady state to another. The identification of the model parameters must describe the nature of the process based on the nature of the time response function. Then, based on the approximation of the obtained object response, the model coefficients are defined [44].

If we assume that the process is described by the first-order homogeneous differential equation with the input function in the form of a step function

$\frac{d y(t)}{d t}+\frac{1}{T} y(t)=\frac{K}{T} u(t)$

then we obtain a solution in the form of Eq. (2)

$y(t)=y(t=0) \exp \left(\frac{-t}{T}\right)+K\left(1-\exp \left(\frac{-t}{T}\right)\right)+C_{0}$

where $y(t)$ is the output value (tool edge reduction $K E$ ), $u(t)$ is the input function (material removal rate), $T$ is the time constant parameter, and $K$ is the gain parameter. The parameter $T$ for $T>0$ can be interpreted as the period. For $t=T$, we achieve a $63 \%$ steady-state wear (for $t=3 T$, we achieve a $95 \%$ steadystate wear). The parameter $K$ can be interpreted as gain (maximum value at equilibrium).

Each of the model parameters supplies information about the tool wearing process. Based on the evolution of tool edge reduction over time, it is possible to estimate the steady-state tool wear (Fig. 12).

After passing through the period of stable operation of the tool and constant wear intensity, the tool wear accumulation occurs, which can be defined as the process of elementary wear phenomena accumulation, which can be described by a first-order equation. The accumulating agent of these phenomena can be described by the equation in the form

$\frac{\mathrm{T}_{\mathrm{i}} \cdot \mathrm{dy}}{\mathrm{dt}}=\mathrm{u}(\mathrm{t})$

where the input signal is Eq. (1) describing the ramp of the signal. Thus, we obtain two dynamic processes connected in series, described by Eqs. (1) and (3), the solution of which is the convolution of these two differential equations. After the solution, we get

$y(t)=\frac{K \cdot t}{T_{i}}-\frac{K \cdot t}{T_{i}}+\frac{K \cdot t}{T_{i}} \exp \left(\frac{-t}{T}\right)+C_{0}$

for an input signal in the form of a unit step function.

The technological issue in thread cutting concerns the change of the position of the tip of the tool while turning a titanium thread as a result of tool edge reduction (Fig. 11). The research discussed in [45], taking into account the guidelines on the impact of tool edge reduction on the accuracy of the thread, found that when the blade shortening reaches a value exceeding $5 \mu \mathrm{m}$, the position of the tip of the tool in the CNC program should be modified to maintain the thread quality at the assumed level.

Taking into account the assumed thread quality, especially when cutting materials such as titanium alloys, the tool is able to reach a critical state very quickly. This may limit the possibility of achieving the assumed accuracy of the thread. To solve this problem, two different tool edge reduction models were analyzed: the first one with decreasing intensity and the second one with increasing intensity. The lifetime of each model over its useful life is different for different cutting conditions. Tests of titanium alloys cut with carbide tools allowed to identify the parameters of the tool edge reduction model in time (Fig. 12).

The study of tool wear during the machining of titanium alloys shows that when cutting threads at ambient temperature, the wear (tool edge reduction) after the first thread was made and was so large that it required the tool tip position correction before the next tool infeed. However, in the case of cooling with liquid nitrogen, it was only necessary after the first three parts were completed, since the wear intensity in the second case was much lower.

The number of workpieces varies depending on the titanium alloy and cooling conditions (with the assumed correction of the tool tip position). For machining threads from grade 2 titanium alloys without cooling, the estimated value of the parts produced was 10, while for cooling with liquid nitrogen, the expected number was higher and increased to 14 . In turn, for machining threads with Ti grade 5, the estimated number of details produced was significantly higher both for cutting at ambient temperature without cooling, where it was 29 , and for cryogenic cooling, where the estimated number of threads made was 49 . This shows that in thread cutting, assisted by the tool wear model, it allows the tool position to be corrected and more threads can be produced to meet the quality requirements with the same tool. The addition of cryogenic conditions enables an additional increase in the number of correctly made threads.

\section{Conclusions}

The machinability of titanium alloys is most often considered from the point of view of the efficiency of the cutting process, i.e., referring to the cutting speed and tool wear. In this work, the scope of research has been extended to include the possibility of thread cutting and the possibility of achieving the assumed thread quality.

Titanium alloys are considered to be difficult-to-cut materials. This relates to their low thermal conductivity and their chemical reactivity at high temperatures with most materials used, with a tendency to weld to the cutting tool. Improvement 


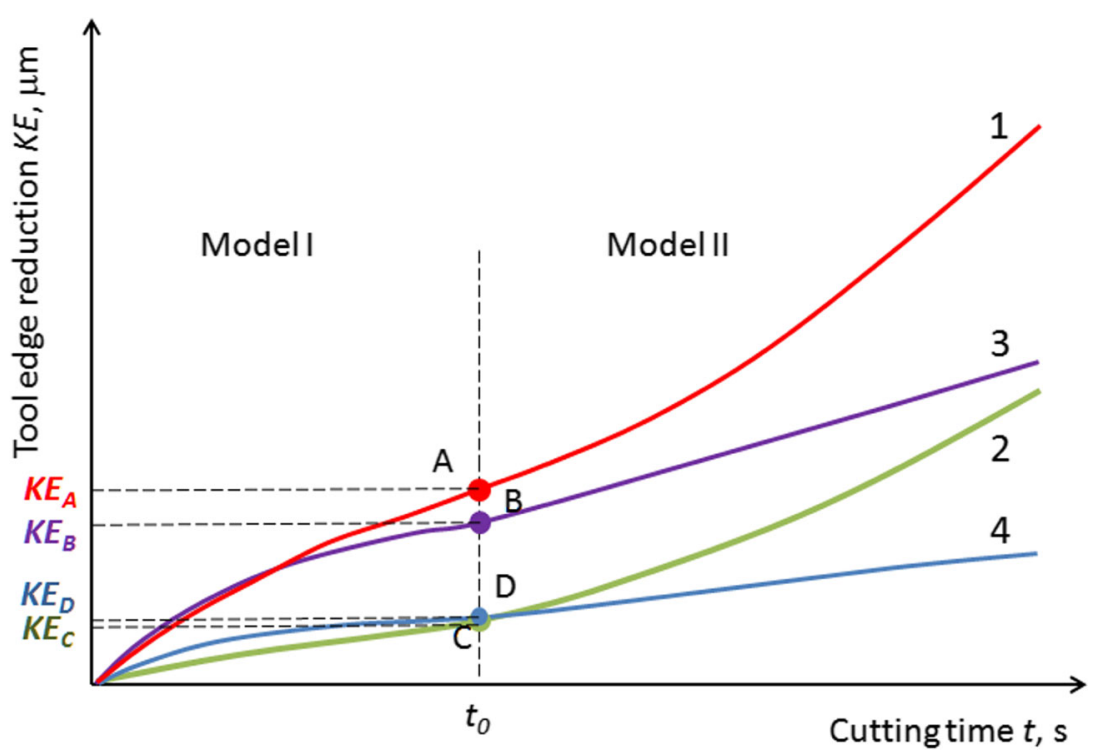

\begin{tabular}{|c|c|c|c|c|c|}
\hline Model I: & \multicolumn{4}{|c|}{$y(t)=y(t=0) \exp \left(\frac{-t}{T}\right)+K\left(1-\exp \left(\frac{-t}{T}\right)\right)+C_{0}$} & $C_{0}=0$ \\
\hline & \multicolumn{2}{|c|}{$T^{-1}$} & \multicolumn{2}{|c|}{$K \cdot T^{-1}$} & $K$ \\
\hline 1 - Ti Grade 2 dry & \multicolumn{2}{|c|}{0.056} & \multicolumn{2}{|c|}{0.27} & 4.85 \\
\hline 2 - Ti Grade 2 LN2 & \multicolumn{2}{|c|}{0.028} & \multicolumn{2}{|c|}{0.072} & 2.55 \\
\hline 3-Ti Grade 5 dry & \multicolumn{2}{|c|}{0.12} & \multicolumn{2}{|c|}{0.35} & 2.84 \\
\hline 4-Ti Grade 5 LN2 & \multicolumn{2}{|c|}{0.16} & \multicolumn{2}{|c|}{0.18} & 1.11 \\
\hline \multirow[t]{2}{*}{ Model II: } & \multicolumn{4}{|c|}{$y(t)=\frac{K \cdot t}{T_{i}}-\frac{K \cdot T}{T_{i}}+\frac{K \cdot T}{T_{i}} \exp \left(\frac{-t}{T}\right)+C_{0}$} & $=K E\left(t_{0}\right)$ \\
\hline & $K E\left(t_{0}\right)$ & $K$ & $T$ & $T_{i}$ & $K \cdot T_{i}^{-1}$ \\
\hline 1 - Ti Grade 2 dry & 1.94 & 13975.75 & 992568.4 & 1.90 & 7338.56 \\
\hline 2 - Ti Grade 2 LN2 & 0.32 & 54.36 & 46142.23 & 0.25 & 212.78 \\
\hline 3 - Ti Grade 5 dry & 0.27 & 0.016 & 0.0001 & 0.12 & 0.13 \\
\hline 4-Ti Grade 5 LN2 & 0.31 & 0.014 & 0.0001 & 0.20 & 0.072 \\
\hline
\end{tabular}

Fig. 12 Identification of tool wear model

in machinability in tests was obtained by freezing the workpiece before machining. This allowed to lower the temperature in the cutting zone and, consequently, to improve the quality of the machined thread.

The tests were carried out for titanium alloys of grades 2 and 5 by thread turning with coated and uncoated carbide tools. Liquid nitrogen was used to pre-cool the workpiece in cryogenic machining. The study of tool wear and its influence on the accuracy of the thread was carried out using optical microscopy, SEM, and EDS. The final conclusions follow directly from the results of the experiments.

1. In the case of liquid nitrogen cooling, the wear of the tool was lower than in dry conditions: by $64 \%$ on average in the case of Ti grade 2 and by $52 \%$ in the case of Ti-6Al$4 \mathrm{~V}$. Due to the temperature generated, which tends to be concentrated at the cutting edge closest to the tool nose of the insert, the wear in the curvilinear part $\mathrm{C}$ was the highest. The values of $\mathrm{VBc}$ after $43 \mathrm{~s}$ of turning of Ti grade 2 do not exceed $0.4 \mathrm{~mm}$ for dry cutting and $0.1 \mathrm{~mm}$ for cryogenic cutting. The use of cryogenic cooling reduces the tool nose wear for both grades of titanium alloys.

2. Analysis of the tool rake face contour information allowed assessment of the impact of the cutting time on changes in the geometrical shape of the tool, including its shortening (tool edge reduction). Changes in the shape of the tool contour affect the accuracy of machining, i.e., the geometry of the thread being machined. The study of tool wear during machining of titanium alloys shows that for thread cutting at ambient temperature, the progressive tool wear after completing the first thread required correction of the tool tip position due to the tool edge reduction, while in the case of liquid nitrogen cooling, this was necessary 
only after completing the first three workpieces, because the intensity of wear in the second case was much lower.

3. The adhesion of the workpiece material to the tool (builtup edge) permitted the tool material to be torn out by passing chips. This is clearly seen on the SEM image and EDS maps, where fragments of adhesive material and its uneven distribution are clearly visible. SEM images of Ti alloys in dry cutting show the exposed part of the tool with the visible TiAlN coating, immediately adjacent to the substrate material. For Ti grade 5, the chips adhering to the edge of the tool have a segmented (serrated) form.

4. In turning thread in conditions of liquid nitrogen cooling for Ti grade 2, the entire tool rake surface is covered with oxidized material. In the case of cutting of Ti-6Al-4V in cryogenic conditions, the material also adheres to the tool. The tungsten distribution map shows that there is no work material stuck on the cutting edge of the tool and the tool material (WC-Co) is visible.

5. The identification of the tool wear model over time during the machining of titanium alloys enabled the verification of the hypothesis concerning the description of the wear process as a system of two dynamic models described by Eqs. (1) and (3). The parameters of the equations were identified on the basis of the data obtained from the experiment. Thanks to the use of dynamic models, the parameters of which have a physical interpretation, it is possible to compare the course of the tool wear process for different cutting conditions. The estimates of the number of threads produced, presented at the end of Section 3, clearly show the beneficial effect of cryogenic cooling on the tool life, assuming a specific thread tolerance.

\section{Declarations}

Ethics approval The authors have obtained the necessary authority for publication.

The paper has not been published previously, that it is not under consideration for publication elsewhere, and that if accepted it will not be published elsewhere in the same form, in English or in any other language, without the written consent of the publisher.

The paper does not contain material which has been published previously, by the current authors or by others, of which the source is not explicitly cited in the paper.

Conflicts of interest The authors declare no competing interests.

Open Access This article is licensed under a Creative Commons Attribution 4.0 International License, which permits use, sharing, adaptation, distribution and reproduction in any medium or format, as long as you give appropriate credit to the original author(s) and the source, provide a link to the Creative Commons licence, and indicate if changes were made. The images or other third party material in this article are included in the article's Creative Commons licence, unless indicated otherwise in a credit line to the material. If material is not included in the article's Creative Commons licence and your intended use is not permitted by statutory regulation or exceeds the permitted use, you will need to obtain permission directly from the copyright holder. To view a copy of this licence, visit http://creativecommons.org/licenses/by/4.0/.

\section{References}

1. Akyildiz HK (2013) Evaluating of cutting forces in thread machining. Int J Adv Manuf Technol 68:1601-1612

2. Jawahir IS, Puleo DA, Schoop J (2016) Cryogenic machining of biomedical implant materials for improved functional performance, life and sustainability. Procedia CIRP 46:7-14

3. Yumak $\mathrm{N}$ et al (2017) Effect of cryogenic and aging treatments on low-energy impact behaviour of $\mathrm{Ti}-6 \mathrm{Al}-4 \mathrm{~V}$ alloy. Trans Nonferrous Metals Soc China 27:514-526

4. Hamdan SH et al (2014) Surface finish when threading titaniumbased alloy under dry machining. J Mech Eng Sci (JMES) 7:10621069

5. Ezugwu EO, Wang ZM (1997) Titanium alloys and their machinability - a review. J Mater Process Technol 68(3):262-274

6. Sheikh-Ahmad J, Bailey JA (1997) Flow instability in the orthogonal machining of CP titanium. J Manuf Sci Eng 119:307-313

7. Aramcharoen A (2016) Influence of cryogenic cooling on tool wear and chip formation in turning of titanium alloy. Procedia CIRP 46: $83-86$

8. Barry J, Byrne G, Lennon D (2001) Observations on chip formation and acoustic emission in machining Ti-6Al-4V alloy. Int J Mach Tool Manu 41:1055-1070

9. Nabhani F (2001) Machining of aerospace titanium alloys. Robot Comput Integr Manuf 17:99-106

10. Dhananchezian M, Kumar MP (2011) Cryogenic turning of the Ti6Al-4V alloy with modified cutting tool inserts. Cryogenics 51(1): $34-40$

11. Damir A, Sadek A, Attia H (2018) Characterization of machinability and environmental impact of cryogenic turning of Ti-6Al-4V. Procedia CIRP 69:893-898

12. Hong SY, Ding Y, Jeong WC (2001) Friction and cutting forces in cryogenic machining of Ti-6Al-4V. Int J Mach Tools Manuf 41: 2271-2285

13. Bermingham $\mathrm{M}$ et al (2011) New observations on tool life, cutting forces and chip morphology in cryogenic machining Ti-6Al-4V. Int J Mach Tools Manuf 51(6):500-511

14. Strano M, Chiappini E, Tirelli S, Albertelli P, Monno M (2013) Comparison of Ti6Al4V machining forces and tool life for cryogenic versus conventional cooling. Proc Inst Mech Eng B J Eng Manuf 227(9):1403-1408

15. Ajay K, Khanna N (2017) A review on cryogenic machining of super alloys used in aerospace industry. Procedia Manuf 7:191-197

16. Hong SY, Ding Y (2001) Cooling approaches and cutting temperatures in cryogenic machining of Ti-6Al-4V. Int J Mach Tools Manuf 41(10): 1417-1437

17. Newman ST, Shokrani A (2019) A new cutting tool design for cryogenic machining of Ti-6Al-4V titanium alloy. Materials 12(477):1-14

18. Bordin A, Bruschi S, Ghiotti A, Bariani PF (2015) Analysis of tool wear in cryogenic machining of additive manufactured Ti6Al4V alloy. Wear 328-329:89-99

19. Bordin A, Sartori S, Bruschi S, Ghiotti A (2017) Experimental investigation on the feasibility of dry and cryogenic machining as sustainable strategies when turning Ti6Al4V produced by additive manufacturing. J Clean Prod 142:4142-4151 
20. Sartori S, Moro L, Ghiotti A, Bruschi S (2017) On the tool wear mechanisms in dry and cryogenic turning additive manufactured titanium alloys. Tribol Int 105:264-273

21. Shokrani A, Dhokia V, Muñoz-Escalona P, Newman ST (2013) State-of-the-art cryogenic machining and processing. Int $\mathrm{J}$ Comput Integr Manuf 26(7):616-648

22. Kaixuan $\mathrm{G}$ et al (2014) Effect of cryogenic treatment on wear resistance of Ti-6Al-4V alloy for biomedical applications. J Mech Behav Biomed Mater 30:131-139

23. Hong SY, Markus I, Jeong WC (2001) New cooling approach and tool life improvement in cryogenic machining of titanium alloy $\mathrm{Ti}-$ 6Al-4V. Int J Mach Tools Manuf 41:2245-2260

24. Kaixuan G et al (2013) Effect of cryogenic treatment and aging treatment on the tensile properties and microstructure of Ti-6Al4V alloy. Mater Sci Eng A 584:170-176

25. Rotella G, Dillon OW Jr, Umbrello D, Settineri L, Jawahir IS (2014) The effects of cooling conditions on surface integrity in machining of Ti6Al4V alloy. Int J Adv Manuf Technol 71:47-55

26. Dornfeld DA, Kim JS, Dechow H, Hewson J, Chen LJ (1999) Drilling burr formation in titanium alloy, Ti-6AI-4V. CIRP Ann Manuf Technol 48:73-76

27. Sartori S, Pezzato L, Dabalà M, Maurizi Enrici T, Mertens A, Ghiotti A, Bruschi S (2018) Surface integrity analysis of Ti6Al4V after semi-finishing turning under different low-temperature cooling strategies. JMEPEG 27:4810-4818

28. ISO 68-1 (1998) 1998, ISO general purpose screw threads - Basic profile - Part 1: Metric screw threads

29. Pramanik A, Littlefair G (2015) Machining of titanium alloy (Ti6Al-4V) - theory to application. Mach Sci Technol 19(1):1-49

30. Sutter G, List G (2013) Very high speed cutting of Ti-6Al-4V titanium alloy - change in morphology and mechanism of chip formation. Int J Mach Tool Manu 66:37-43

31. Vardex threading insert information, https://www.vargus.com/ vardex

32. Carmex threading insert information, http://www.carmex.com/

33. Gill SS et al (2011) Investigation on wear behaviour of cryogenically treated TiAlN coated tungsten carbide inserts in turning. Int $\mathrm{J}$ Mach Tool Manu 51:25-33

34. Bermingham $\mathrm{M}$ et al (2012) A comparison of cryogenic and high pressure emulsion cooling technologies on tool life and chip morphology in Ti-6Al-4V cutting. J Mater Process Technol 212(4): $752-765$
35. Bagherzadeh A, Budak E (2018) Investigation of machinability in turning of difficult-to-cut materials using a new cryogenic cooling approach. Tribol Int 119:510-520

36. Nouari M, Makich H (2013) Experimental investigation on the effect of the material microstructure on tool wear when machining hard titanium alloys: Ti-6Al-4V and Ti-555. Int J Refract Met Hard Mater 41:259-269

37. Courbon C, Pusavec F, Dumont F, Rech J, Kopac J (2013) Tribological behaviour of Ti6Al4V and Inconel 718 under dry and cryogenic conditions - application to the context of machining with carbide tools. Tribol Int 66:72-82

38. SreeramaReddy TV, Sornakumar T, VenkataramaReddy M, Venkatram R (2009) Machinability of C45 steel with deep cryogenic treated tungsten carbide cutting tool inserts. Int J Refract Met Hard Mater 27:181-185

39. Padmakumar $\mathrm{M}$ et al (2018) Tribological behaviour of cryogenically treated WC-9Co cemented carbide. Mater Today: Proc 5:77977807

40. Chen-hui XIE et al (2015) Effects of deep cryogenic treatment on microstructure and properties of $\mathrm{WC}-11 \mathrm{Co}$ cemented carbides with various carbon contents. Trans Nonferrous Metals Soc China 25: 3023-3028

41. Zawada-Tomkiewicz A (2008) Measurement uncertainty assessment in machine vision system for tool wear estimation. Coordinate Measuring Techn:175-183

42. ISO 3685 (1993) Tool life testing with single-point turning tools. https://www.iso.org/standard/9151.html

43. Sulaiman MA et al (2015) Tool life performance of coated carbide tool on titanium alloy extra low interstitials. Jurnal Teknologi (Sci Eng) 77(1):85-93

44. Zawada-Tomkiewicz A, Ściegienka R (2011) Monitoring of a micro-smoothing process with the use of machined surface images. Metrol Meas Syst XVIII/3:419-428

45. Zawada-Tomkiewicz A, Wierucka I (2018) A case study in technological quality assurance of a metric screw thread. Measurement 114:208-217

Publisher's note Springer Nature remains neutral with regard to jurisdictional claims in published maps and institutional affiliations. 